\title{
Elevated central venous pressure is associated with increased mortality in pediatric septic shock patients
}

\author{
Seung Jun Choi, Eun-Ju Ha, Won Kyoung Jhang and Seong Jong Park
}

\begin{abstract}
Background: Central venous pressure (CVP) is an important factor affecting capillary blood flow, and it is associated with poor outcomes in adult septic shock patients. However, whether a similar association exists in pediatric patients remains unclear.

Methods: We retrospectively analyzed data from patients admitted to our pediatric intensive care unit (PICU) between February 2009 and July 2015. Patients were divided into two groups-survivors and nonsurvivors-according to 28-day mortality. The associations between (a) mortality and CVP at 6, 24, 48, and $72 \mathrm{~h}$ after initiating treatment for established septic shock was analyzed and (b) initial serum lactic acid levels and 6-h CVP.

Results: Two hundred twenty-six patients were included in this study, and the mortality rate was 29.6\% (67 deaths, nonsurvivor group). Initial serum lactic acid levels, Pediatric Risk of Mortality (PRISM) III score, and Vasoactive-Inotropic Score (VIS) within $24 \mathrm{~h}$ after PICU admission were significantly higher in the nonsurvivors than in survivors $(1.3[0.9,2.4]$ vs. $3.9[1.6,8.0] \mathrm{mmol} / \mathrm{I}, 11.0[7.0,15.0]$ vs. $17.0[10.0,21.5], 12.0[7.0,25.0]$ vs. $22.5[8.0,55.0]$, respectively with $p$-values $<0.001,<0.001$, and 0.009 , respectively). In addition, compared to survivors, a greater percentage of nonsurvivors required mechanical ventilation (92.5\% vs. 51.6\%, $p<0.001$ ) and showed a greater extent of fluid overload at $48 \mathrm{~h}$ after admission (3.9\% vs. 1.9\%, $p=0.006)$, along with higher 6-h CVP $(10.0[7.0,16.0]$ vs. 8.0 [5.0, 11.0] mmHg, $p<0.001)$. Patient survival according to levels of CVP (CVP $<8 \mathrm{mmHg}$, CVP $8-12 \mathrm{mmHg}$, or CVP $>12 \mathrm{mmHg}$ ) showed that the CVP $>12-\mathrm{mmHg}$ group had significantly greater mortality rates $(50.0 \%, p=0.002)$ than the other groups $(21.3 \%$ and 27. 5\%). Furthermore, multivariate analysis identified significant associations of CVP $>12 \mathrm{mmHg}$, serum lactic acid levels, and the need for mechanical ventilation with mortality (OR: 2.74, 1.30, and 12.51, respectively; 95\% Cl: 1.11-6.72, 1.12-1. 50, and 4.12-37.96, respectively).
\end{abstract}

Conclusions: Elevated CVP is an independent risk factor for mortality in pediatric septic shock patients.

Keywords: Central venous pressure, Mortality, Pediatrics, Septic shock

\section{Background}

Central venous pressure (CVP) is frequently used to monitor the complex circulatory status of critically ill patients [1]. Although the utility of CVP is currently being questioned, $[2,3]$ it is still widely used as an indicator of hemodynamic status, and achieving a CVP > $8 \mathrm{mmHg}$ is considered standard policy during fluid resuscitation (Early Goal Directed Therapy, EGDT) [4].

\footnotetext{
* Correspondence: goodjobman79@naver.com

Division of Pediatric Critical Care Medicine, Department of Pediatrics, Asan Medical Center Children's Hospital, University of Ulsan College of Medicine, 388-1 Pungnap-2 dong, Songpa-gu, Seoul 138-736, Republic of Korea
}

CVP is affected by cardiac function and blood volume returning to the heart $[5,6]$, and CVP elevation, which is frequently observed in critically ill patients, is associated with disturbances in venous return and microcirculatory blood flow [7]. Reports in recent literature suggest that alterations in microcirculatory blood flow are associated with poor outcomes in adult patients with severe sepsis [8-10], and an association between elevated CVP and mortality in adult septic shock patients has been studied [11-13]. However, no studies have examined the association between CVP and clinical outcomes in pediatric septic shock patients. Thus, we aimed to 
elucidate the association between CVP and mortality in pediatric septic shock patients admitted to a pediatric intensive care unit (PICU). In addition, we sought to analyze the correlation between CVP and serum lactic acid levels, which is another important parameter that reflects microcirculatory blood flow.

\section{Methods}

A retrospective medical review of patients admitted to the 14-bed, level-III PICU at the Asan Medical Center Children's Hospital, Seoul, Korea from February 2009 to July 2015, was performed. Septic shock was defined as sepsis accompanied by cardiovascular dysfunction [14], and only patients definitively diagnosed with septic shock were included in the study. The mainstay of treatment for septic shock at our unit is based on the Surviving Sepsis Campaign (2008, updated in 2012) [4, 15].

The patients were divided into two groups (survivors vs. nonsurvivors) according to 28-day mortality. Demographic information, data on laboratory results, clinical status, including comorbidities and sources of infection, the severity of illness based on the Pediatric Risk of Mortality III (PRISM III) score, Vasoactive-Inotropic Score (VIS), duration of PICU stay, and the requirement for mechanical ventilation. The VIS was calculated as follows [16]:

VIS = Dopamine dose $(\mathrm{mcg} / \mathrm{kg} / \mathrm{min})+$ Dobutamine dose $(\mathrm{mcg} / \mathrm{kg} / \mathrm{min})+100 \times$ Epinephrine dose $(\mathrm{mcg} / \mathrm{kg} / \mathrm{min})+$ $10 \times$ Milrinone dose $(\mathrm{mcg} / \mathrm{kg} / \mathrm{min})+10,000 \times$ Vasopressin dose (units $/ \mathrm{kg} / \mathrm{min})+100 \times$ Norepinephrine dose $(\mathrm{mcg} /$ $\mathrm{kg} / \mathrm{min})$.

The CVP at 6, 24, 48, and $72 \mathrm{~h}$ after identification and initiation of treatment for septic shock (henceforth abbreviated as 6-h CVP, 24-h CVP, 48-h CVP, and 72-h CVP, respectively) and the extent of fluid overload during the 3 days following initiation of treatment for septic shock were also ascertained. The following equation was adopted for calculating the extent of fluid overload (\%):

$\{[$ Total fluid intake (L) - total fluid output (L)]/ICU admission body weight (kg) $\}$ * $100(\%)$.

According to the Surviving Sepsis Guidelines (2), study participants were divided into three groups: (1) $\mathrm{CVP}<$ $8 \mathrm{mmHg}$; (2) CVP 8-12 $\mathrm{mmHg}$; and (3) CVP > $12 \mathrm{mmHg}$ at each time point of CVP measurement, i.e., $6,24,48$, and $72 \mathrm{~h}$ after admission. We then analyzed whether the patients with CVP in the recommended range $(8-12 \mathrm{mmHg})$ had a survival advantage over the other groups.

SPSS software (ver. 18) was used for statistical analysis. Continuous and categorical variables were compared between survivors and nonsurvivors, and analyzed using the Wilcoxon rank sum test or the chi-square test, as applicable. The one-way analysis of variance and Bonferroni post-hoc test were used to compare the three CVP-based groups and the odds ratios in the CVP $>12$ -
mmHg group. The Kruskal-Wallis test was used to compare serum lactic acid levels in the three CVP groups. Variables selected according to their $p$-values in the univariate analysis were tested in a multivariate logistic regression model. A p-value $<0.05$ was considered significant for all analyses.

This study was approved by the institutional review board of the Asan Medical Center. The need for informed consent was exempted because of the retrospective nature of the study.

\section{Results}

Our records indicated that 278 patients with a diagnosis of septic shock had been admitted to the PICU during the study period. Among these, patients without CVP measurements or those without CVP data within $6 \mathrm{~h}$ of diagnosis $(N=19)$, patients who died within $72 \mathrm{~h}$ after admission to the PICU $(N=14)$, patients who did not fulfill the above definition of septic shock $(N=11)$, and patients with incomplete CVP records $(N=8)$ were excluded. Therefore, data from 226 patients were used in this study. Catheters were predominantly inserted in the femoral vein $(n=188,83.2 \%)$, followed by the internal jugular $(n=21,9.3 \%)$ and the subclavian $(n=17,7.5 \%)$. Of the 226 patients included, 67 died, resulting in a mortality rate of $29.6 \%$ and these patients formed the nonsurvivor group. The remaining 159 patients formed the survivor group.

Compared to the survivors, the median [IQR] PRISM III score and the VIS within $24 \mathrm{~h}$ of admission were significantly higher in the nonsurvivors $(11.0[7.0,15.0]$ vs. $17.0[10.0,21.5]$ and $12.0[7.0,25.0]$ vs. $22.5[8.0$, 55.0]; $p<0.001$ and $p=0.009$, respectively), and a greater portion of the nonsurvivors required mechanical ventilation $(92.5 \%$ vs. $51.6 \%, \mathrm{p}<0.001)$. Moreover, the median [IQR] lactic acid levels obtained immediately after admission was higher in the nonsurvivors than in the survivors $(3.9[1.6,8.0] \mathrm{mmol} / \mathrm{L}$ vs. $1.3[0.9$, $2.4 \mathrm{mmol} / \mathrm{L}, p<0.001)$. The extent of fluid overload within the first $24 \mathrm{~h}$ did not vary significantly among the groups, but was significantly greater in nonsurvivors than in survivors at $48 \mathrm{~h}(3.9 \%$ vs. $1.9 \%, p=0.006)$. The 6-h CVP was significantly lower in survivors than in nonsurvivors $(8.0[5.0,11.0]$ vs. $10.0[7.0,16.0)]$ $\mathrm{mmHg}, \mathrm{p}<0.001$; Table 1 ).

Patients were divided into three groups according to 6-h CVP and survival compared among them (Table 2). Mortality in the CVP $>12-\mathrm{mmHg}$ group $(50.0 \%)$ was significantly higher than that in the CVP $<8 \mathrm{mmHg}$ (21.3\%) or CVP $8-12 \mathrm{mmHg}(27.5 \%)$ groups, but mortality was not significantly different between the $\mathrm{CVP}<8-\mathrm{mmHg}$ group and the CVP $8-12-\mathrm{mmHg}$ group. Next, patients were consecutively divided into three CVP groups for each time point $(6,24,48$, and $72 \mathrm{~h})$ as 
Table 1 Patient characteristics

\begin{tabular}{|c|c|c|c|}
\hline Characteristics & $\begin{array}{l}\text { Survivors } \\
(n=159)\end{array}$ & $\begin{array}{l}\text { Non-survivors } \\
(n=67)\end{array}$ & $p$ value \\
\hline Age, years & $4.0(0.6,12.7)$ & $4.6(0.8,14.4)$ & 0.273 \\
\hline Male, n (\%) & $83(52.2)$ & $33(49.3)$ & 0.771 \\
\hline \multicolumn{4}{|l|}{ Coexisting conditions, n (\%) } \\
\hline Cardiac disease & $44(27.7)$ & $12(17.9)$ & 0.132 \\
\hline Hemato-oncologic disease & $32(20.1)$ & $19(28.4)$ & 0.222 \\
\hline Neurologic disease & $25(15.7)$ & $7(10.4)$ & 0.404 \\
\hline Pulmonary disease & $20(12.6)$ & $13(19.4)$ & 0.216 \\
\hline Chronic renal disease & $20(12.6)$ & $7(10.4)$ & 0.667 \\
\hline Gastrointestinal disease & $12(7.5)$ & $6(9.0)$ & 0.789 \\
\hline Endocrinologic disease & $6(3.8)$ & $3(4.5)$ & 0.805 \\
\hline PRISM III score & $11.0(7.0,15.0)$ & $17.0(10.0,21.5)$ & $<0.001$ \\
\hline $\begin{array}{l}\text { Duration of PICU stay } \\
\text { (days) }\end{array}$ & $12.0(7.0,35.0)$ & $11.5(4.0,18.0)$ & 0.062 \\
\hline $\begin{array}{l}\text { Mechanical ventilation, } \\
\text { n (\%) }\end{array}$ & $82(51.6)$ & $62(92.5)$ & $<0.001$ \\
\hline VIS & $12.0(7.0,25.0)$ & $22.5(8.0,55.0)$ & 0.009 \\
\hline $\begin{array}{l}\text { Lactic acid at admission, } \\
(\mathrm{mmol} / \mathrm{l})\end{array}$ & $1.3(0.9,2.4)$ & $3.9(1.6,8.0)$ & $<0.001$ \\
\hline $\begin{array}{l}\text { Brain natriuretic peptide } \\
(\mathrm{pg} / \mathrm{mL})\end{array}$ & $\begin{array}{l}286.0(62.5 \\
1015.0)\end{array}$ & $\begin{array}{l}461.0(74.0 \\
1624.5)\end{array}$ & 0.271 \\
\hline $\begin{array}{l}\text { Proven microorganisms, } \\
\mathrm{n}(\%)\end{array}$ & $91(57.2)$ & $45(67.2)$ & 0.183 \\
\hline Gram-positive & $52(32.7)$ & $26(38.8)$ & 0.444 \\
\hline Staphylococci & $24(15.1)$ & $14(20.9)$ & 0.331 \\
\hline Streptococci & $10(6.3)$ & $4(6.0)$ & 0.928 \\
\hline Enterococcus & $15(9.4)$ & $7(10.4)$ & 0.814 \\
\hline Other & $3(1.9)$ & $1(1.5)$ & 0.837 \\
\hline Gram-negative & $34(21.4)$ & $13(19.4)$ & 0.858 \\
\hline Klebsiella & $15(9.4)$ & $2(3.0)$ & 0.106 \\
\hline Pseudomonas & $5(3.1)$ & $3(4.5)$ & 0.697 \\
\hline E.coli & $5(3.1)$ & $4(6.0)$ & 0.456 \\
\hline Acinetobacter & $6(3.8)$ & $4(6.0)$ & 0.488 \\
\hline Other & $3(1.9)$ & $0(0)$ & 0.557 \\
\hline Fungi & $5(3.1)$ & $6(9.0)$ & 0.088 \\
\hline Candida & $5(3.1)$ & $6(9.0)$ & 0.088 \\
\hline CVP at $6 \mathrm{~h}, \mathrm{mmHg}$ & $8.0(5.0,11.0)$ & $10.0(7.0,16.0)$ & $<0.001$ \\
\hline \multicolumn{4}{|l|}{ Fluid overload, \% } \\
\hline $0-24 \mathrm{~h}$ & $0.7(-0.6,2.6)$ & $1.3(-0.2,3.6)$ & 0.100 \\
\hline $0-48 \mathrm{~h}$ & $1.9(-0.5,5.7)$ & $3.9(0.9,9.3)$ & 0.006 \\
\hline $0-72 \mathrm{~h}$ & $3.8(0.3,7.9)$ & $5.1(1.8,10.9)$ & 0.055 \\
\hline
\end{tabular}

The results are presented as the median (interquartile range) or as the number (\%). PICU, Pediatric Intensive Care Unit; PRISM III, Pediatric Risk of Mortality III; VIS, Vasoactive Inotropic Scores

described above (Table 3) and the adjusted odds ratio for the group with CVP $>12 \mathrm{mmHg}$ for each time point (h) was obtained. The odds ratio was low in $\mathrm{CVP}<$
Table 2 Survival according to the 6 h CVP

\begin{tabular}{|c|c|c|c|}
\hline & $\mathrm{CVP}<8 \mathrm{mmHg}^{\mathrm{a}}$ & CVP 8-12 mmHg & $\mathrm{CVP}>12 \mathrm{mmHg}^{\mathrm{c}}$ \\
\hline$\overline{\text { Total }}$ & $89(100.0)$ & $91(100.0)$ & $46(100.0)$ \\
\hline Survivors & $70(78.7)$ & $66(72.5)$ & $23(50.0)$ \\
\hline Non-survivors* & 19 (21.3) & $25(27.5)$ & $23(50.0)$ \\
\hline
\end{tabular}

$8 \mathrm{mmHg}$ and CVP $8-12-\mathrm{mmHg}$ groups than in the $\mathrm{CVP}>12-\mathrm{mmHg}$ group.

Next, lactic acid levels at admission was compared among the three 6-h-CVP groups (Fig. 1), and was not significantly different between the $\mathrm{CVP}<8 \mathrm{mmHg}$ and CVP $8-12-\mathrm{mmHg}$ groups $(1.5[1.0,2.7] \mathrm{mmol} / \mathrm{L}$ vs. 1.5 $[0.8,3.2] \mathrm{mmol} / \mathrm{L}, p=0.952)$. However, the CVP > $12-\mathrm{mmHg}$ group had significantly higher lactic acid levels than in the other groups $(2.7[1.4,5.9] \mathrm{mmol} / \mathrm{L}$, $p=0.001$ and $p=0.002$, respectively). Furthermore, lactic acid levels was greater in nonsurvivors than in survivors, when analyzed within each of the three 6-h-CVP groups $(1.4[0.9,2.3]$ vs. $2.9[1.2,8.8], p=0.009$ in the CVP $<8$-mmHg group; $1.3[0.9,2.6]$ vs. $2.4[1.1,4.6], p=0.021$ in the CVP 8-12-mmHg group; and 1.4 [1.0, 2.1] vs. 5.3 [2.8, 14.4], $p<0.001$ in the CVP $>12$-mmHg group). Variables with significant association in univariate analyses were analyzed in a multivariate logistic regression model (Table 4), which revealed that CVP $>12 \mathrm{mmHg}$, lactic acid levels, and requirement for mechanical ventilation were the factors significantly associated with mortality with odds ratios $(95 \%$ CI) of 2.74 (1.11-6.72), 1.30 (1.12-1.50), and 12.51 (4.12-37.96), respectively.

\section{Discussion}

From a retrospective analysis of 226 cases, we showed that elevated CVP is associated with increased mortality

Table 3 Odds ratio for death based on CVP values

\begin{tabular}{ll}
\hline CVP group & Adjusted Odds Ratio versus CVP $>12 \mathrm{mmHg}$ \\
\hline $6 \mathrm{~h}$ & \\
CVP $<8 \mathrm{mmHg}$ & $0.452(0.288-0.707)$ \\
CVP $8-12 \mathrm{mmHg}$ & $0.539(0.341-0.854)$ \\
$24 \mathrm{~h}$ & \\
CVP $<8 \mathrm{mmHg}$ & $0.298(0.184-0.485)$ \\
CVP 8-12 mmHg & $0.481(0.292-0.791)$ \\
$48 \mathrm{~h}$ & \\
CVP $<8 \mathrm{mmHg}$ & $0.299(0.178-0.502)$ \\
CVP 8-12 mmHg & $0.420(0.247-0.712)$ \\
$72 \mathrm{~h}$ & \\
CVP $<8 \mathrm{mmHg}$ & $0.371(0.221-0.621)$ \\
CVP 8-12 mmHg & $0.512(0.294-0.892)$
\end{tabular}

CVP, central venous pressure Odds ratios are shown with associated $95 \%$ confidence intervals 




Fig. 1 Boxplots of initial lactic acid levels at admission compared among three groups ( $\mathrm{CVP}<8 \mathrm{mmHg}, 8-12 \mathrm{mmHg}$, and $>12 \mathrm{mmHg}$ ) *For differences in lactic acid levels in each of the CVP groups; $p<0.05$ was considered to be statistically significant

in pediatric septic shock patients. In particular, mortality risk increased by $>2$-fold in patients with $\mathrm{CVP}>$ $12 \mathrm{mmHg}$ compared to those with minimally elevated CVP. Consistent with previous studies in the pediatric population [17-23], we also found that univariate analyses identified the extent of fluid overload at $48 \mathrm{~h}$ after admission, initial lactic acid levels, PRISM III score, VIS, and the requirement for mechanical ventilation as factors associated with mortality. However, only CVP > $12 \mathrm{mmHg}$, lactic acid, and requirement for mechanical ventilation remained significant in multivariate analysis.

In our study, the 6-h CVP was lower in the survivors, which is consistent with the results from previous studies in adult patients that showed that mean 6-h and 48-h CVP was lower in survivors than in nonsurvivors [12]. Furthermore, at all time points tested $(6 \mathrm{~h}, 24 \mathrm{~h}, 48 \mathrm{~h}$, and $72 \mathrm{~h}$ ), the association between CVP and mortality showed that the $\mathrm{CVP}<8-\mathrm{mmHg}$ group had a higher survival rate than the $\mathrm{CVP}>12-\mathrm{mmHg}$ group. This is also

Table 4 Multivariate analysis of the independent risk for mortality

\begin{tabular}{llll}
\hline Variables & $\begin{array}{l}\text { Adjusted } \\
\text { odds ratio }\end{array}$ & $\begin{array}{l}\text { 95\% confidence } \\
\text { interval }\end{array}$ & $p$ value \\
\hline CVP $>12$ mmHg & 2.74 & $1.11-6.72$ & 0.028 \\
0-48 h fluid overload & 0.98 & $0.92-1.05$ & 0.709 \\
VIS & 1.00 & $0.98-1.01$ & 0.974 \\
Lactic acid & 1.30 & $1.12-1.50$ & $<0.001$ \\
PRISM & 1.05 & $0.99-1.11$ & 0.057 \\
Mechanical ventilation & 12.51 & $4.12-37.96$ & $<0.001$ \\
\hline
\end{tabular}

CVP, central venous pressure; PRISM III, Pediatric Risk of Mortality III; VIS, Vasoactive Inotropic Scores consistent with previous results that show that patients whose 12 -h CVP was $<8 \mathrm{mmHg}$ had the highest survival rate, whereas those patients whose 12-h CVP was > $12 \mathrm{mmHg}$ had the lowest survival rate [11].

There was no significant difference in mortality rate between the groups CVP $<8 \mathrm{mmHg}$ and CVP $8-12 \mathrm{mmHg}$. Although EGDT is still considered the standard of care in managing severe sepsis and septic shock patients [4], recent studies have failed to yield similar positive results [24-27]. Septic shock is the resultant of not only volume depletion but also profound vasodilation along with microcirculatory dysfunction [28]. Moreover, some studies have questioned the usefulness of CVP in evaluating response to fluid resuscitation [29]. Therefore, although it may not be necessary to establish a specific target for CVP to guide fluid resuscitation, it may be more appropriate to interpret CVP elevation (particularly if the CVP was > $12 \mathrm{mmHg}$, as in our study) as a warning sign of impaired microcirculation.

In addition, we also analyzed the association between the elevated CVP and serum lactic acid levels, an indicator of the patients' microcirculatory status. According to Vellinga et al., the percentage of small, perfused vessels was significantly lower in the high-CVP group (> $12 \mathrm{mmHg}$ ) than the low-CVP group $(\leq 12 \mathrm{mmHg})$, which reflects the cardinal role of CVP in regulating microcirculatory perfusion during sepsis [30]. That organ perfusion and function (e.g., kidney, liver, and lung) are determined by CVP was also underscored by Wang et al. [13]. Although we found that there was no significant difference in lactic acid levels between the CVP $<8-\mathrm{mmHg}$ and CVP $8-12-\mathrm{mmHg}$ groups, the CVP $>12-\mathrm{mmHg}$ group 
showed a higher lactic acid levels, which may be attributable to impaired microcirculatory blood flow and decreased organ perfusion in these patients.

Fluid overload has also been mentioned as a factor associated with poor outcomes in previous studies [31-35], and is in line with our results from univariate analyses. Although the statistical significance of fluid overload was not retained in multivariable analysis, it is undeniable that overall volume status is an important factor in assessing patients and making appropriate treatment decisions in clinical settings. Therefore, we think it wise to assess the intravascular and microcirculatory status, and simultaneously but cautiously interpret CVP numbers, while keeping in mind that multiple factors other than volume status also affect CVP.

Our study is limited by its retrospective nature and small sample size, as the data pertain to a single PICU. The retrospective nature of this study also prevented us from obtaining information on heart function, intraabdominal pressure, or intrathoracic pressure, all of which can also affect CVP. Therefore, we were not able to investigate the etiology of elevated CVP. However, we found that elevated CVP was indeed the parameter associated with poor outcome, which may serve as a valuable pivotal point in septic shock treatment in the pediatric population. Third, we did not analyze the effects, if any, of the different types of intravenous fluids used for volume resuscitation, as the impact of fluid volume and type in septic shock patients on mortality has been previously addressed [36]. However, as there is no consensus regarding the most appropriate fluid type for resuscitation other than crystalloid, we deem this an issue to be pursued in future research. Finally, future studies are required to validate our results in addressing the association between CVP and mortality on a larger scale using randomized, prospective studies.

\section{Conclusions}

We showed that an elevated CVP (particularly if CVP > $12 \mathrm{mmHg}$ ) was associated with increased mortality in pediatric septic shock patients, and that further studies are required to analyze the difference in the outcome, if any, between groups with $\mathrm{CVP}<8 \quad \mathrm{mmHg}$ and 8-12 mmHg.

\footnotetext{
Abbreviations

CVP: Central venous pressure; EGDT: Early Goal Directed Therapy; ICU: Intensive care unit; PICU: pediatric intensive care; PRISM: Pediatric Risk of Mortality; VIS: Vasoactive-Inotropic Score
}

\section{Acknowledgements}

Not applicable.

\section{Availability of data and material}

Anonymous data used in this study is available upon request from the corresponding author.

\section{Funding}

This research received no specific grant from any funding agency, commercial, or not-for-profit sectors.

\section{Authors' contributions}

SJ Choi designed the study, carried out statistical analyses, interpreted data, and wrote the draft and final version of the manuscript. EJ Ha collected data. WK Jhang critically revised the manuscript. SJ Park supervised the whole process, critically revised the manuscript, and approved the final version. All authors read and approved the final version of the manuscript.

\section{Ethics approval and consent to participate}

This study was approved by the Institutional Review Board (IRB) of the Asan Medical Center (Number: 2016-1084). The IRB confirmed that no ethical approval for such retrospective analysis of anonymous data is necessary. The need for informed consent was exempted because of the retrospective nature of the study

\section{Consent for publication}

Not applicable.

\section{Competing interests}

The authors declare that they have no competing interests.

\section{Publisher's Note}

Springer Nature remains neutral with regard to jurisdictional claims in published maps and institutional affiliations.

Received: 16 May 2017 Accepted: 7 February 2018

Published online: 13 February 2018

\section{References}

1. Li DK, Wang XT, Liu DW. Association between elevated central venous pressure and outcomes in critically ill patients. Ann Intensive Care. 2017;7:83-9.

2. Michard F, Alaya S, Zarka V, et al. Global end-diastolic volume as an indicator of cardiac preload in patients with septic shock. Chest. 2003;124(5):1900-8.

3. Marik PE, Cavallazzi R. Does the central venous pressure predict fluid responsiveness? An updated meta-analysis and a plea for some common sense. Crit Care Med. 2013;41(7):1774-81.

4. Dellinger RP, Levy MM, Rhodes A, et al. Surviving sepsis campaign: international guidelines for Management of Severe Sepsis and Septic Shock. 2012. Crit Care Med. 2013;41:580-637.

5. Magder S, Bafaqeeh F. The clinical role of central venous pressure measurements. J Intensive Care Med. 2007;22(1):44-51.

6. Gelman S. Venous function and central venous pressure: a physiologic story. Anesthesiology. 2008;108(4):735-48

7. Berlin DA, Bakker J. Starling curves and central venous pressure. Crit Care. 2015;19(1):1-8.

8. De Backer D, Donadello K, Sakr Y, et al. Microcirculatory alterations in patients with severe sepsis: impact of time of assessment and relationship with outcome. Crit Care Med. 2013:41:791-9.

9. Sakr Y, Dubois MJ, De Backer D, et al. Persistent microcirculatory alterations are associated with organ failure and death in patients with septic shock. Crit Care Med. 2004:32:1825-31.

10. De Backer D, Creteur J, Preiser JC, et al. Microvascular blood flow is altered in patients with sepsis. Am J Respir Crit Care Med. 2002;166:98-104.

11. Boyd JH, Forbes J, Nakada TA, et al. Fluid resuscitation in septic shock: a positive fluid balance and elevated central venous pressure are associated with increased mortality. Crit Care Med. 2011;39(2):259-65.

12. Varpula M, Tallgren M, Saukkonen $\mathrm{K}$, et al. Hemodynamic variables related to outcome in septic shock. Intensive Care Med. 2005;31(8):1066-71.

13. Wang XT, Yao B, Liu DW, et al. Central venous pressure dropped early is associated with organ function and prognosis in septic shock patients: retrospective observational study. Shock. 2015;44(5):426-30.

14. Goldstein B, Giroir B, Randolph A. International pediatric sepsis consensus conference: definitions for sepsis and organ dysfunction in pediatrics. Pediatr Crit Care Med. 2005:6:2-8.

15. Dellinger RP, Levy MM, Carlet JM, et al. Surviving sepsis campaign: international guidelines for Management of Severe Sepsis and Septic Shock. 2008. Crit Care Med. 2013;36:296-327. 
16. Gaies MG, Jeffries HE, Niebler RA, et al. Vasoactive-inotropic score (VIS) is associated with outcome after infant cardiac surgery: an analysis from the Peditric cardiac critical care consortium (PC ${ }^{4}$ ) and virtual PICU system registries. Pediatr Crit Care Med. 2014;15(6):529-37.

17. Kim YA, Ha EJ, Jhang WK, et al. Early blood lactate area as a prognostic marker in pediatric septic shock. Intensive Care Med. 2013;39:1818-23.

18. Shapiro NI, Homel MD, Talmor D, et al. Serum lactates as a predictor of mortality in emergency department patient with infection. Ann Emerg Med. 2005:45:524-8

19. Dugas MA, Proulx F, de Jaeger A, et al. Markers of tissue hypoperfusion in pediatric septic shock. Intensive Care Med. 2000;26:75-83.

20. Ibrahiem SK, Galal YS, Youssef MR, et al. Prognostic markers among Egyptian children with sepsis in the intensive care units, Cairo University hospitals. Allergol Immunopathol. 2016;44(1):46-53.

21. Kutko MC, Calarco MP. Flaherty MB, et al. Mortality rates in pediatric septic shock with and without multiple organ system failure. Pediatr Crit Care Med. 2003;4(3):333-7.

22. Haque A, Siddiqui NR, Munir O, et al. Association between vasoactive-inotropic score and mortality in pediatric septic shock. Indian Pediatr. 2015;52(4):311-3.

23. Fiser RT, West NK, Bush AJ, et al. Outcome of severe sepsis in pediatric oncology patients. Pediatr Crit Care Med. 2005;6(5):531-6.

24. Mouncey PR, Osborn TM, Power S, et al. Trial of early, goaldirected resuscitation for septic shock. N Engl J Med. 2015;372:1301-11.

25. Yealy DM, Kellum JA, Huang DT, et al. A randomized trial of protocol-based care for early septic shock. N Engl J Med. 2014;370:1683-93.

26. Peake SL, Delasney A, Bailey M, et al. Goal-directed resuscitation for patients with early septic shock. N Engl J Med. 2014;371:1496-506.

27. Angus DC, Barnato AE, Bell D, et al. A systematic review and meta-analysis of early goal-directed therapy for septic shock: the ARISE, ProCESS and ProMISe investigators. Intensive Care Med. 2015;41:1549-60.

28. Marik P, Bellomo R. A rational approach to fluid therapy in sepsis. Br J Anaesth. 2016;116(3):339-49.

29. Marik PE, Baram M, Vahid B. Does central venous pressure predict fluid responsiveness? A systematic review of the literature and the tale of seven mares. Chest. 2008;134(1):172-8.

30. Vellinga NA, Ince C, Boerma EC. Elevated central venous pressure is associated with impairment of microcirculatory blood flow in sepsis: a hypothesis generating post hoc analysis. BMC Anesthesiol. 2013;13:17.

31. Sirvent JM, Ferri C, Baro A, et al. Fluid balance in sepsis and septic shock as a determining factor of mortality. Am J Emerg Med. 2015;33:186-9.

32. Alsous F, Khamiees M, DeGirolamo A, et al. Negative fluid balance predicts survival in patients with septic shock: a retrospective pilot study. Chest. 2000;117: 1749-54.

33. Acheampong A, Vincent JL. A positive fluid balance is an independent prognostic factor in patients with sepsis. Crit Care. 2015;19:251.

34. de Oliveira FS, Freitas FG, Ferreira EM, et al. Positive fluid balance as a prognostic factor for mortality and acute kidney injury in severe sepsis and septic shock. J Crit Care. 2015:30:97-101.

35. Abulebda K, Cvijanovich NZ, Thomas NJ, et al. Post-ICU admission fluid balance and pediatric septic shock outcomes: a risk-stratified analysis. Crit Care Med. 2014;42:397-403.

36. Smith SH, Perner A. Higher vs. lower fluid volume for septic shock: clinical characteristics and outcome in unselected patients in a prospective, multicenter cohort. Crit Care. 2012;16(3):R76

\section{Submit your next manuscript to BioMed Central and we will help you at every step:}

- We accept pre-submission inquiries

- Our selector tool helps you to find the most relevant journal

- We provide round the clock customer support

- Convenient online submission

- Thorough peer review

- Inclusion in PubMed and all major indexing services

- Maximum visibility for your research

Submit your manuscript at www.biomedcentral.com/submit 